\title{
Accuracy of printed models obtained from intraoral scanning
}

\author{
- Fernando Igai Departamento de Prótese, Faculdade de Odontologia, Universidade de São Paulo (USP), São Paulo, \\ SP, Brasil - Washington Steagall Junior Disciplina de Dentística, Faculdade de Odontologia, Universidade Nove \\ de Julho, São Paulo, SP, Brasil - Pedro Tortamano Neto Departamento de Prótese, Faculdade de Odontologia, \\ Universidade de São Paulo (USP), São Paulo, SP, Brasil
}

ABSTRACT | Objectives: To compare the accuracy of two methods for the manufacturing of physical models: I) intraoral scanning and resin-printed models; and II) addition silicone impression and gypsum model. Materials and methods: A dental manikin was used as the master model and compared with five gypsum models (g1) and five resin printed models (g2) by analyzing linear measurements at four sites (M1, M2, M3, and M4) using an image measuring instrument. The mean values of the experimental models were compared to those of the master model using one-sample t-test. The samples of each group at the same site were compared with an independent t-test. For all tests, a significance level of $5 \%$ (0.05) was considered. Results: The confidence intervals from M1, M2, and M4 sites for both gypsum and resin models presented statistically lower linear distance when compared to the reference values. At $\mathrm{m}_{3}$, the mean value for the gypsum models was not statistically different from the reference mean value ( $\mathrm{p}>0.05)$; however, resin-printed models presented a statistically different mean value ( $<$ 0.05), as well as lower values of linear distance. Conclusions: When compared to gypsum models, resin- printed models differed greatly from the master model, indicating the need for standardizing the printing protocol, for its variables may influence printed models accuracy.

DESCRIPTORS | Dental Models; Three-Dimensional Printing; Dimensional Accuracy.

RESUMO | Acurácia de Modelos Impressos obtidos a partir de Escaneamento Intra-oral • Objetivos: Comparar a acurácia de dois métodos de fabricação de modelos físicos: I) escaneamento intra-oral e modelos impressos em resina; e II) moldagem de silicone de adição e modelo de gesso. Materiais e métodos: Utilizou-se um manequim odontológico como modelo mestre, o qual foi comparado a cinco modelos de gesso (g1) e cinco modelos impressos em resina (g2) por meio de análises de medições lineares em quatro sítios de medição (M1, M2, M3 e M4) com um instrumento de medição por imagem. Os valores médios dos modelos experimentais foram comparados aos do modelo mestre utilizando-se o Teste-t. Para um mesmo local, as amostras de cada grupo foram comparadas por meio do Teste-t para amostras independente. Para todos os testes, foi adotado o nível de significância de 5\% (0,05). Resultados: Os intervalos de confiança dos sítios M1, M2, e M4 para os modelos de gesso e resina apresentaram distância linear estatisticamente menor quando comparados aos valores do modelo de referência. Em M3, o valor médio dos modelos de gesso não foi estatisticamente diferente do valor médio da referência ( $>>0,05)$; entretanto, os modelos impressos em resina apresentaram valor médio estatisticamente diferente $(\mathrm{p}<0,05)$, bem como menores valores de distância linear. Conclusões: Quando comparados aos modelos de gesso, os modelos impressos em resina diferiram muito do modelo mestre, indicando a necessidade de padronização do protocolo de impressão, pois suas variáveis podem influenciar no nível de acurácia dos modelos impressos. 


\section{INTRODUCTION}

Among other factors, the successful outcome of prosthetic treatment in fixed prosthodontics depends upon the passive fit and adaptation of the restoration. Therefore, the precision and fidelity of the working model from which the prosthesis will be fabricated is very important. If the impressions produced by the dentist result in a clinically accurate working model, the dental prosthetic technician will be able to achieve a good restoration. Thus, an accurate working model ensures a well-fitted restoration with good adaptation, providing a more predictable treatment and long-lasting outcomes.

New technology enables the manufacturing of prosthetic restoration in a digital workflow, based on digital models obtained from the scanning of gypsum working models. The use of computer-aided design and computer-aided manufacturing (CAD-CAM) in this digital workflow produces an even more reliable restoration, decreases the number of sessions, and improves the speed and predictability of the treatment, as well as patients' comfort and acceptance.,

Intraoral scanners enabled a direct scanning of patients' mouth, eliminating the need for the obtention of the gypsum model. With the advent of this technology, these models have been replaced by a digital model in which restorations will be both designed and manufactured, thus providing clinically acceptable restorations. ${ }^{3,4}$ These models also represent an interesting way of storing clinical cases, once digital files do not require physical storage. However, physical models are often required at certain clinical and laboratory stages, as well as for some legal issues, so that digital models obtained from intraoral scanning and CAD-CAM technology can be printed through rapid prototyping technologies, ${ }^{5,6}$ approaching digital ${ }^{7,8}$ and gypsum models.9,10

Nevertheless, the costs inherent to the acquisition of the intraoral scanner and the $3 \mathrm{D}$ printer are rather high, ${ }^{1}$ increasing even further before the need of high-skilled professionals. ${ }^{11}$ Considering that the technical features of gypsum models ${ }^{12}$ have clinically acceptable precision, ${ }^{13}$ thus comprising a still a very reliable option for application in Dentistry, students should investigate whether the increased costs of the printed model are justifiable. Thus, this study sought to compare a master model with two methods for the manufacturing of physical models. Our first null hypothesis was that the gypsum and printed models would present no significant differences in relation to the master model. The second null hypothesis was that the values obtained for the two experimental groups would show no significant differences at each measurement site.

\section{MATERIAL AND METHODS}

The experiment was conducted using a dental manikin (P-Oclusal, Sao Paulo, Brazil) as a master model, including both intact dental elements and some elements with partial and total dental prosthesis. Two methods for the manufacturing of physical models were analyzed, forming two experimental groups: G1, composed of five gypsum models $(n=5)$ obtained from impressions of the master model; and G2, composed of five resin models ( $n=5$ ) obtained from the intraoral scanning of the master model, using the Trios Pod Colors scanner (3 shape, Denmark), and printed using the Digital Wax 020D printer (DWS, Italy).

Models were printed on polyvinyl siloxane (Express, 3M ESPE, 3M, Brazil), using the double impression technique. One gypsum model was produced from each cast, using the high-strength type IV New Fuji Rock gypsum (GC AMERICA Inc., Alsip IL, USA) at the ratio of $20 \mathrm{~mL}$ of water to $100 \mathrm{~g}$ of gypsum. To avoid the formation of bubbles, gypsum was manipulated with the aid of a vacuum spreader (Polidental, Ind. e Comércio Ltd., Brazil) and removed from the casts after 40 minutes, according to the manufacturer's instructions.

For resin models manufacturing, the master model was scanned five times by an operator trained 
by the scanner manufacturer, thus avoiding bias. Each scan file generated a single model. The scanning strategy was also standardized, following the buccal region form tooth 17 up to tooth 27 , passing on to the occlusal region from tooth 27 up to tooth 17 , and covering the lingual region on the same direction as the former.
The scanned files were converted into STL format, and models were printed including the gingival and teeth region. Tongue base and palatal region were removed from resin models. Figure 1 shows the master, gypsum, and resin models used in the study.



FIGURE 1 || Models used in the study. A: Master model; B: Gypsum model; C: Resin model.

For comparing G1 and G2 models with the master model, linear measurements were performed at four sites: M1, M2, M3, and M4 - M1 was the distance from the mesiobuccal cusp of tooth 17 and tooth 27; M2 was the distance from the distobuccal region of tooth 13 and of tooth 23; M3 was the distance from the distal region of tooth 17 and the mesial region of tooth 13; and M4 was the height of tooth 16 mesiobuccal cusp in the dental manikin. Figure 2 illustrates the four measurement sites.



FIGURE 2 | M1, M2, M3, and M4 measurement sites. 
The linear measurements of the models at the four sites were performed using the Quick Vision ELF (Mitutoyo®, Japan) image measuring machine. This machine has a monochrome camera that generates grayscale images - the principle for performing the measurements. To avoid interexaminer bias, all measurements were performed by a single specialist at Mitutoyo $®$ Sul Americana (Mitutoyo ${ }^{\circledR}$ Sul Americana, Suzano, SP, Brazil).

The first null hypothesis was verified by comparing the mean values of linear measurements obtained at M1, M2, M3, and M4 for both G1 and G2 to the mean values of the master model. Moreover, the discrepancy values of each measurement site were compared to reference values (zero value) by subtracting the average absolute values of $\mathrm{G} 1$ and $\mathrm{G} 2$ linear measurements from the master model measurements (reference values).

To verify the second null hypothesis, G1 mean value in M1 was compared to G2 absolute values in M1. The same process was performed at the other measurement sites (M2 to M4).

Statistical analyses were performed using the MINITAB 17 program (MINITAB Inc. v.17.1.o, PA, USA). The first hypothesis was verified using the onesample Student's $t$-test for each experimental group. In turn, the second hypothesis was tested using a two-sample Student's $t$-test for each comparison (M1 gypsum x M1 resin, M2 gypsum x M2 resin, and so on). Data normality was verified by the Shapiro-Wilk's test, indicating normal distribution ( $\mathrm{p}>0.05)$.

\section{RESULTS}

Table 1 shows linear measurements for $\mathrm{G} 1$ and G2 in comparison with the reference values (master model) at the four measurement sites. The confidence intervals obtained for both experimental groups did not include the reference values for M1, M2, and M4 sites (59.73 mm, $38.17 \mathrm{~mm}$, and 7.80 mm, respectively), showing that the one-sample Student's $t$-test was significant. When compared to reference values, these means presented statistically lower values of linear distance ( $\mathrm{p}<0.05)$. At $\mathrm{M}_{3}$, the confidence interval of G1 $(-0.16 \pm 0.01 \mathrm{~mm})$ included the reference value of $40.77 \mathrm{~mm}$, so that this group mean $(40.70 \pm 0.07 \mathrm{~mm})$ was not statistically different from the reference value ( $p$ > 0.05). However, the G2 confidence interval did not include the reference value at the same site, being statistically different $(\mathrm{p}<0.05)$ and presenting lower values of linear distance - as seen in other sites. Table 2 and the graph in Figure 3 illustrate the discrepancy between the mean values of experimental groups and the master model (zero value). This table also shows that, in both experimental groups, some measurement sites showed significant differences when compared to the master model $(\mathrm{p}<0.05)$, while others showed no show significant differences ( $\mathrm{p}>0.05)$.

TABLE 1 | Comparison between each mean and the reference value using the one-sample Student's $t$-test.

\begin{tabular}{c|c|c|c|c|c|c|c|c|c|c} 
Sites & Material & Mean & SD & SEM & $\mathbf{t}$ & Sig. (2-tailed) & Mdiff & 95\% LCIdiff & 95\% UCIdiff \\
\hline \multirow{2}{*}{ M1 } & Gypsum & 59.26 & 0.06 & 0.03 & -16.34 & $8.20 \mathrm{E}-05^{*}$ & -0.47 & -0.55 & -0.39 \\
& Resin & 59.26 & 0.32 & 0.15 & -3.21 & $3.25 \mathrm{E}-02^{*}$ & -0.47 & -0.87 & -0.06 \\
\hline \multirow{2}{*}{ M2 } & Gypsum & 38.05 & 0.03 & 0.01 & -8.44 & $1.08 \mathrm{E}-03^{*}$ & -0.12 & -0.16 & -0.08 \\
& Resin & 37.86 & 0.06 & 0.03 & -11.47 & $3.29 \mathrm{E}-04^{*}$ & -0.31 & -0.39 & -0.23 \\
\hline \multirow{2}{*}{ M3 } & Gypsum & 40.70 & 0.07 & 0.03 & -2.31 & $8.23 \mathrm{E}-02$ & -0.07 & -0.16 & 0.01 \\
& Resin & 39.88 & 0.35 & 0.16 & -5.73 & $4.59 \mathrm{E}-03 *$ & -0.89 & -1.32 & -0.46 \\
\hline \multirow{2}{*}{ M4 } & Gypsum & 7.54 & 0.16 & 0.07 & -3.56 & $2.37 \mathrm{E}-02 *$ & -0.26 & -0.46 & -0.06 \\
& Resin & 7.37 & 0.03 & 0.01 & -34.49 & $4.22 \mathrm{E}-06^{*}$ & -0.43 & -0.46 & -0.39 \\
\hline
\end{tabular}


TABLE 2 | Discrepancy values between gypsum models and resin models in relation to the master model (absolute values - reference values). Descriptive statistics for the discrepancy data (original data - reference)

\begin{tabular}{c|c|c|c|c|c|c|c|c|c|c|c|c|c|}
\hline Variable & Sites & Mean & SE & SD & Var & Min & Q1 & Med & Q3 & Max \\
\hline \multirow{3}{*}{ Gypsum } & M1 & -0.472 & 0.029 & 0.065 & 0.004 & -0.520 & -0.515 & -0.490 & -0.420 & -0.360 \\
& M2 & -0.124 & 0.015 & 0.033 & 0.001 & -0.160 & -0.155 & -0.130 & -0.090 & -0.090 \\
& M3 & -0.072 & 0.031 & 0.070 & 0.005 & -0.170 & -0.135 & -0.080 & -0.005 & 0.000 \\
& M4 & -0.258 & 0.073 & 0.162 & 0.026 & -0.500 & -0.420 & -0.200 & -0.125 & -0.100 \\
\hline \multirow{3}{*}{ Resin } & M1 & -0.466 & 0.145 & 0.324 & 0.105 & -0.720 & -0.715 & -0.660 & -0.120 & -0.020 \\
& M2 & -0.310 & 0.027 & 0.060 & 0.004 & -0.370 & -0.370 & -0.300 & -0.255 & -0.230 \\
& M3 & -0.892 & 0.156 & 0.348 & 0.121 & -1.36 & -1.235 & -0.810 & -0.590 & -0.470 \\
& M4 & -0.428 & 0.012 & 0.028 & 0.001 & -0.460 & -0.455 & -0.430 & -0.400 & -0.400 \\
\hline
\end{tabular}

$\mathbf{S E}=$ standard error; $\mathbf{S D}=$ standard deviation; $\mathbf{V a r}=$ variance; $\mathbf{M i n}=$ minimum; $\mathbf{Q 1}=$ first quartile; $\mathbf{M e d}=$ median; $\mathbf{Q} \mathbf{3}=$ third quartile; $\mathbf{M a x}=$ maximum . $\mathbf{N}=5$

Unit $=\mathrm{mm}$

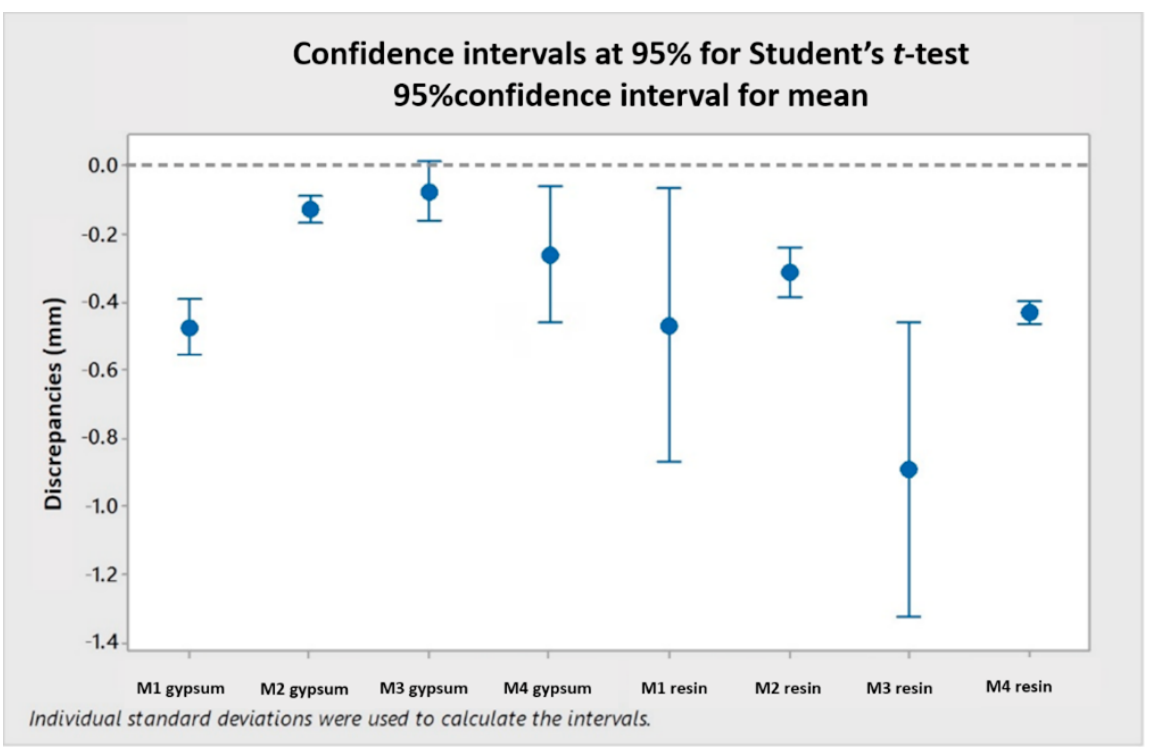

FIGURE 3 | Comparison of mean values of discrepancy between gypsum and resin models.

Table 3 shows mean values comparison between G1 and G2. The two-sample Student's $t$-test between G1 and $\mathrm{G}_{2}$ at M2, M3, and $\mathrm{M}_{4}$ sites was significant. In all sites, $\mathrm{G} 1$ presented greater linear distance values than G2. In M2, G > G2 (p = o,000307). In $\mathrm{M}_{3}, \mathrm{G} 1>\mathrm{G} 2$ ( $\left.\mathrm{p}=0.000858\right)$. In $\mathrm{M}_{4}, \mathrm{G} 1>\mathrm{G} 2$ ( $p=0.0497)$. At M1, however, G1 and G2 comparison ( $p=0.97)$ was not significant.

TABLE 3 | Two-sample independent Student's t-test between G1 (Gypsum) and G2 (Resin) at M1, M2, M3, and M4

\begin{tabular}{c|c|c|c|c|c|c|c|}
\hline Sites & $\mathbf{t}$ & Sig. (2-sample) & Mdiff & StdEdiff & 95\% LCIdiff & 95\% UCIdiff \\
\hline M1 & -0.04 & 0.97 & -0.01 & 0.15 & -0.35 & 0.34 \\
\hline M2 & 6.05 & $3.07 \mathrm{E}-04 *$ & 0.19 & 0.03 & 0.12 & 0.26 \\
\hline M3 & 5.17 & $8.58 \mathrm{E}-04 *$ & 0.82 & 0.16 & 0.45 & 1.19 \\
\hline M4 & 2.31 & $0.0497 *$ & 0.17 & 0.07 & 0.00 & 0.34 \\
\hline
\end{tabular}

$\mathbf{t}=$ obtained $t$ value; StdEdiff $=$ standard error difference; Mdiff $=$ mean difference; $\mathbf{9 5} \%$ LCIdiff $=95 \%$ lower confidence interval of the difference; 95\% $\%$ Cldiff $=95 \%$ upper confidence interval of the difference.

$\mathbf{N}=10 ; \mathbf{d f}=8$

Critical t value $(\mathbf{0 . 0 5 . 8 \mathrm { df } )}=|2.31|$

*significant at $5 \%(0.05)$

Unit $=m m$ 


\section{DISCUSSION}

Our results indicate that measurements of both gypsum and resin models were significantly smaller than those of the master model, except for $\mathrm{M}_{3}$ in the gypsum model (G1). Thus, our first null hypothesis was rejected. Moreover, both experimental groups showed significant differences as to comparisons of each site measurements, except for the M1 site. Thus, our second null hypothesis was likewise rejected. Measurements at the other sites indicated that resin models were smaller than gypsum models. In our study, resin models required a final polymerization process for improving their hardness, which was performed as part of the printing protocol. Such a polymerization led resin models to present a greater shrinkage when compared to gypsum models. In addition, dispersion results showed that resin models tend to present lower repeatability than gypsum models. These findings allow us to infer that gypsum models present a better accuracy than resin models, thus corroborating previous studies. ${ }^{13-16}$

Gypsum models were obtained according to a standardized methodology. The conventional impression was performed using an individual tray with an internal relief, standardizing the impression material thickness and reducing the risk of significant dimensional changes. ${ }^{17}$ Models were also printed using the double impression technique, which contributed to a better dimensional stability. ${ }^{18}$ Moreover, both gypsum and the impression material were manipulated following the manufacturer's instructions, resulting in models with a smaller discrepancy in relation to the master model when compared to resin models. Regardless, the differences observed in gypsum models may be inherent to the manufacturing process.

Resin models were also obtained according to a standardized methodology. All the intraoral scanning was performed by a trained operator and following a single scanning strategy, ${ }^{19,20}$ thus eliminating potential quality and accuracy issues. ${ }^{11}$
The results indicate the need for monitoring the entire printing process of the models - the printer choice, the intraoral scanning strategy, and the model dimensions, - for all stages influence the quality and accuracy of the models. Despite monitoring all these factors, our resin models still showed significant discrepancies with the master model. This finding evinces that resin models will always differ from the master model - a fact the dentist should be aware, thus employing these models only in procedures in which the observed discrepancy will not negatively influence the outcomes.

Another factor that may have influenced these models discrepancy was the material and its color: the resin was translucent and colorless, which hampered the reading by the measuring equipment. This would explain WHY the colored gypsum models showed a smaller discrepancy when compared to resin models.

This study has some limitations. The first one refers to the limited sample size, so that our results should be considered carefully, even with statistical support. The other limitation refers to the impossibility of simulating the clinical conditions that interfere with the quality of the scanning process. ${ }^{21}$ Moreover, further studies should investigate different types of scanners and $3 \mathrm{D}$ printers.

Despite these limitations, a key strength of our study lies on the fact that the comparative measurements were performed in physical models. That is, the analysis was not made through image superimposition programs, thus waiving the need for another scanning process for analyzing resin models while allowing us to observe the influence of the model surface features and finish.

\section{CONCLUSION}

On the conditions of this pilot study, we may conclude that:

- Resin models presented more significant discrepancies with the master model than gypsum models. 
- The printing protocol must be standardized, for its variables can influence resin models accuracy.

\section{REFERENCES}

1. Bhambhani R, Bhattacharya J, Sen SK. Digitization and its futuristic approach in prosthodontics. J Indian Prosthodont Soc. 2013;13(3):165-74. Doi: https://doi.org/10.1007/s13191-012-0181-2

2. Gjelvold B, Chrcanovic BR, Korduner EK, Collin-Bagewitz I, Kisch J. Intraoral Digital Impression Technique Compared to Conventional Impression Technique. A Randomized Clinical Trial. J Prosthodont. 2016;25(4):282-7. Doi: https://doi. org/10.1111/jopr.12410

3. Brawek PK, Wolfart S, Endres L, Kirsten A, Reich S. The clinical accuracy of single crowns exclusively fabricated by digital workflow - the comparison of two systems. Clin Oral Investig. 2013;17(9):2119-25. Doi: https://doi.org/10.1007/ s00784-013-0923-5

4. Boeddinghaus M, Breloer ES, Rehmann P, Wostmann B. Accuracy of single-tooth restorations based on intraoral digital and conventional impressions in patients. Clin Oral Investig. 2015;19(8): 2027-34. Doi: https://doi.org/10.1007/soo784-015-1430-7

5. Dawood A, Marti Marti B, Sauret-Jackson V, Darwood A. 3D printing in dentistry. Br Dent J. 2015;219(11):521-9. Doi: https://doi.org/10.1038/sj.bdj.2015.914

6. Bell A, Ayoub AF, Siebert P. Assessment of the accuracy of a three-dimensional imaging system for archiving dental study models. J Orthod. 2003;30(3):219-23. Doi: https:// doi.org/10.1093/ortho/30.3.219

7. Cuperus AM, Harms MC, Rangel FA, Bronkhorst EM, Schols JG, Breuning KH. Dental models made with an intraoral scanner: a validation study. A J Orthod Dentofacial Orthop. 2012;142(3):308-13. Doi: https://doi.org/10.1016/j. ajodo.2012.03.031

8. Hazeveld A, Huddleston Slater JJ, Ren Y. Accuracy and reproducibility of dental replica models reconstructed by different rapid prototyping techniques. Am J Orthod Dentofacial Orthop. 2014;145(1):108-15. Doi: https://doi.org/10.1016/j. ajodo.2013.05.011

9. Lee SJ, Betensky RA, Gianneschi GE, Gallucci GO. Accuracy of digital versus conventional implant impressions. Clin Oral Implants Res. 2015;26(6):715-9. Doi: https://doi.org/10.1111/clr.12375

10. Kasparova M, Grafova L, Dvorak P, Dostalova T, Prochazka A, Eliasova H, et al. Possibility of reconstruction of dental plaster cast from $3 \mathrm{D}$ digital study models. Biomed Eng Online. 2013;12:49. Doi: https://doi.org/10.1186/1475-925x-12-49
11. Lim JH, Park JM, Kim M, Heo SJ, Myung JY. Comparison of digital intraoral scanner reproducibility and image trueness considering repetitive experience. J Prosthet Dent. 2018;119(2):225-32. Doi: https://doi.org/10.1016/j.prosdent.2017.05.002

12. Alhouri N, McCord JF, Smith PW. The quality of dental casts used in crown and bridgework. Br Dent J. 2004;197(5):261-4. Doi: https://doi.org/10.1038/sj.bdj.4811621

13. Cho SH, Schaefer O, Thompson GA, Guentsch A. Comparison of accuracy and reproducibility of casts made by digital and conventional methods. J Prosthet Dent. 2015;113(4):310-5. Doi: https://doi.org/10.1016/j.prosdent.2014.09.027

14. Ender A, Mehl A. Accuracy of complete-arch dental impressions: a new method of measuring trueness and precision. J Prosthet Dent. 2013;109(2):121-8. Doi: https://doi. org/10.1016/soo22-3913(13)60028-1

15. Kuhr F, Schmidt A, Rehmann P, Wostmann B. A new method for assessing the accuracy of full arch impressions in patients. J Dent. 2016;55:68-74. Doi: https://doi.org/10.1016/j.jdent.2016.10.002

16. Park ME, Shin SY. Three-dimensional comparative study on the accuracy and reproducibility of dental casts fabricated by 3D printers. J Prosthet Dent. 2018;119(5):861.e1-861.e7. Doi: https://doi.org/10.1016/j.prosdent.2017.08.020

17. Kumar V, Aeran H. Evaluation of effect of tray space on the accuracy of condensation silicone, addition silicone and polyether impression materials: an in vitro study. J Indian Prosthodont Soc. 2012;12(3):154-6o. Doi: https://doi. org/10.1007/s13191-012-0124-y

18. Caputi S, Varvara G. Dimensional accuracy of resultant casts made by a monophase, one-step and two-step, and a novel two-step putty/light-body impression technique: an in vitro study. J Prosthet Dent. 2008;99(4):274-81. Doi: https://doi. org/10.1016/s0022-3913(08)60061-x

19. Muller P, Ender A, Joda T, Katsoulis J. Impact of digital intraoral scan strategies on the impression accuracy using the TRIOS Pod scanner. Quintessence Int. 2016;47(4):343-9. Doi: https://doi.org/10.3290/j.qi.a35524

20. Anh JW, Park JM, Chun YS, Kim M, Kim M. A comparison of the precision of three-dimensional images acquired by 2 digital intraoral scanners: effects of tooth irregularity and scanning direction. Korean J Orthod. 2016;46(1):3-12. Doi: https://doi.org/10.4041/kjod.2016.46.1.3

21. Flugge TV, Schlager S, Nelson K, Nahles S, Metzger MC. Precision of intraoral digital dental impressions with iTero and extraoral digitization with the iTero and a model scanner. Am J Orthod Dentofacial Orthop. 2013;144(3):471-8. Doi: https://doi.org/10.1016/j.ajodo.2013.04.017 